\title{
LASER INTERFEROMETER DIAGNOSTICS OF CNC MACHINE TOOLS
}

This paper presents diagnostics of selected CNC machine tools performed with XL80 laser interferometer with XC80 environmental compensation unit, temperature sensors and XR20-W rotary axis calibrator, working together with XL80 laser. Furthermore, the paper includes the methodology and results of conducted linear and angular error measurements, which supplied data for further analysis. The conclusion section presents results of conducted experiment. Measurement results were presented in figures, charts and tables.

Keywords: Manufacturing, CNC machine tools, cutting process diagnostics, diagnostic systems of CNC machine tools, laser interferometer.

\section{Introduction}

Together with the increased demand for high precision of manufactured parts, machine tools and machine tool systems are required to maintain ever-increasing geometric, kinematic, technological and efficiency standards [ $1-5]$. There is a particular demand for advancing efficiency together with machining precision and process simulation [6 - 11]. In order to achieve and maintain precision within several micrometres, control and compensation for a variety of errors is imperative; these include, inter alia, geometric, kinematic, thermal or cutting force induced errors [12 - 19]. For a 3-axis milling centre, for instance, 21 errors can be distinguished. Major errors that ought to be mentioned are as follows: deviations of the X-Axis (position deviation in $\mathrm{X}$-direction (XTX, EXX), straightness deviation in $\mathrm{Y}$ direction (XTY, EYX), straightness deviation in Z-direction (XTZ, EZX), roll around $\mathrm{X}$-axis (XRX, EAX), pitch around $\mathrm{Y}$-axis (XRY, EBX), yaw around Z-axis (XRZ, ECX)), deviations of the Y-axis (position deviation in Y-direction (YTY, EYY), straightness deviation in X-direction (YTX, EXY), straightness deviation in Z-direction (YTZ, EZY), roll around Y-axis (YRY, EBY), pitch around X-axis (YRX, EAY), yaw around Z-axis (YRZ, ECY)), deviations of the Z-axis (position deviation in Z-direction (ZTZ, EZZ), straightness deviation in X-direction (ZTX, EXZ), straightness deviation in Y-direction (ZTY, EYZ), roll around Z-axis (ZRZ, ECZ), pitch around $\mathrm{X}$-axis (ZRX, EAZ), yaw around Y-axis (ZRY, EBZ)) and squareness errors (squareness error between $X$ and $\mathrm{Y}$ axes (XWY), squareness error between $\mathrm{X}$ and $\mathrm{Z}$ axes (XWZ), squareness error between $\mathrm{Y}$ and $\mathrm{Z}$ axes (YWZ)). Although some of these can be significantly reduced, they cannot be completely eliminated [20 - 23]. Numerically controlled machines (machine tools or robots) respond to motions programmed in the machine coordinate system [24]. The precision of these programmed operations depends on the precision of numerically controlled motions, precise geometry of their positioning and the influence of a technological process realised at a given moment. Above all, supervision over the realisation of programmed motions is required.

Machine tool accuracy measurements are normalised and described by ISO-230. The norm sets requirements and specifications regarding geometric accuracy of machine tools for machining metal and wood, together with requirements and specifications regarding measurements and measuring equipment. Polish Norms describe both general methodology of machine tool measurements and specific methods for error motion determination and limiting conditions associated with tolerances [25].

\section{Research methodology}

The test subjects were three $\mathrm{CNC}$ machine tools (Fig. 1), namely, DMU 65 MonoBlock vertical 5-axis machining centre (Fig. 1a), DMC 635 V ECOLINE vertical machining centre (Fig. 1b) and CTX 310 ECOLINE numerical control turning centre (Fig. 1c). The assessment determines positioning error motions in the $\mathrm{X}, \mathrm{Y}, \mathrm{Z}$ axis, particularly, bidirectional accuracy of positioning of a numerically controlled axis A, unidirectional accuracy of positioning of an axis (forward $\mathrm{A} \uparrow$; reverse $\mathrm{A} \downarrow$ ), unidirectional repeatability of positioning

\footnotetext{
* ${ }^{1}$ Jerzy Jozwik, ${ }^{2}$ Ivan Kuric, ${ }^{1}$ Leszek Semotiuk

${ }^{1}$ Department of Production Engineering, Mechanical Engineering Faculty, Lublin University of Technology, Poland

${ }^{2}$ Department of Automation and Production Systems, University of Zilina, Slovakia

E-mail: j.jozwik@pollub.pl
} 
a)

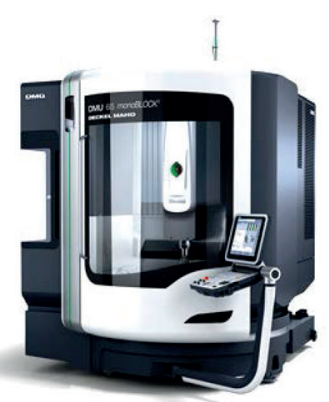

b)

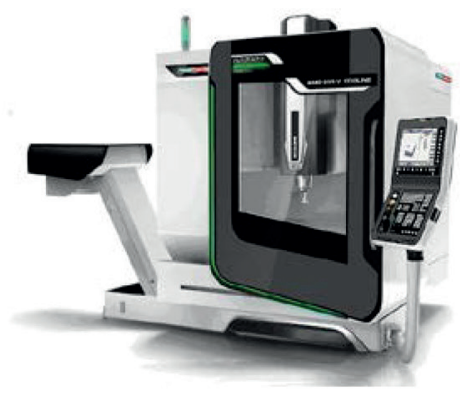

c)

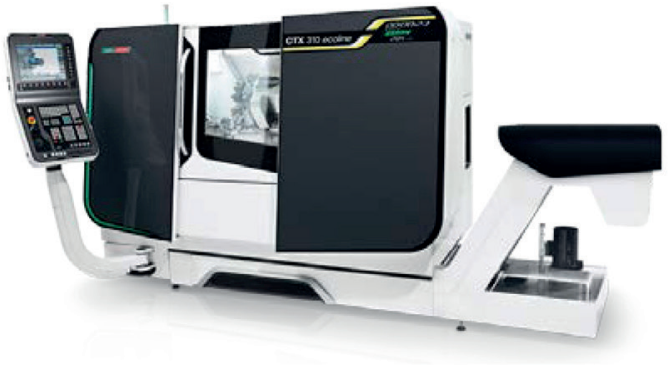

Fig. 1 Analysed machine tools: a) DMU 65 MonoBlock vertical 5-axis machining centre, b) DMC 635 V ECOLINE vertical machining centre, c) CTX 310 ECOLINE numerical control turning centre [26]

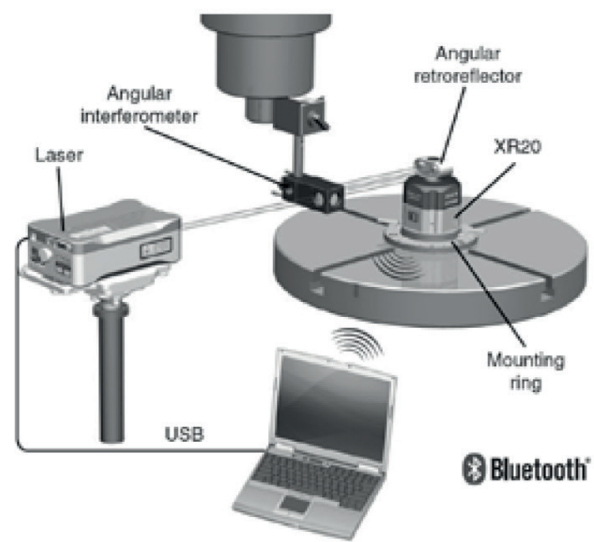

b)

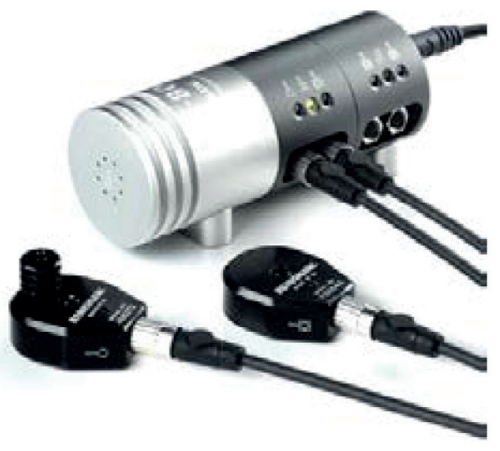

c)

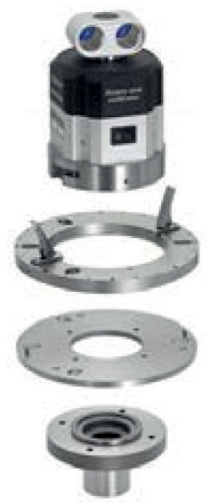

Fig. 2 Renishaw XL80 laser interferometer: a) rotary axis measurement kit, b) XC80 environmental compensation unit with temperature,

c) XR20-W calibrator [27]

(forward $\mathrm{R} \uparrow$; reverse $\mathrm{R} \downarrow$ ) and reversal value of an axis $\mathrm{B}$. The tolerances for the group of analysed machine tools are as follows: $\mathrm{A}=22 \mu \mathrm{m}, \mathrm{A} \uparrow=16 \mu \mathrm{m}, \mathrm{A} \downarrow=16 \mu \mathrm{m}, \mathrm{R} \uparrow=6 \mu \mathrm{m}$, $\mathrm{R} \downarrow=6 \mu \mathrm{m}, \mathrm{B}=10 \mu \mathrm{m}$.

Figure 2 presents XL80 laser interferometer with XR20 calibrator and XC80 environmental compensation unit, allowing the measurement and compensation for linear and angular positioning errors.

Laser interferometer has become a worldwide standard and found application at practically all machine tool manufacturing plants. The setting time is relatively short and direct communication of laser software with the machine controller enables immediate measurement configuration and downloading of the data to a compensation table in the machine's controller.

Figure 3 shows measuring stands during setting and measuring of positioning error motion and positioning repeatability of analysed machine tools (DMC $635 \mathrm{~V}$ ECOLINE vertical machining centre (Fig. 3a), DMU 65 MonoBlock vertical 5-axis machining centre (Fig. 3b) and CTX 310 ECOLINE numerical control turning centre (Fig. 3c). XR20-W unit used with modern Renishaw XL80 interferometers enables measurements of angle deviations of the rotary tables of 5-axis machine tools. As in the case of the linear axis, the measurement is notably fast with the accuracy higher than 1 "/turn.

Table 1 presents environmental parameter reading conditions for the DMC 635 V ECOLINE machining tool.

In addition, the instrument enables dynamic measurement (motion and speed as a function of time) and interpretation of the measurement results for various methodologies (Fourier transform). XR20-W calibrator provides time-efficient and uncomplicated wireless testing of $\mathrm{CNC}$ machines of various types (e.g. 5-axis centres or measuring machines). Moreover, XR20-W calibrator allows measuring of the positioning accuracy of rotary axes, with an accuracy of 1 arc second. XR20-W calibrator is equipped with a handle adapter - an adapter plate, as well as the mounting ring and the centration aid, together constituting a system applicable to a variety of machines and devices, whose configuration and measurement procedure are controlled with RotaryXL software.

DMC $635 \mathrm{~V}$ ecoline vertical machining centre measurement methodology comprised $\mathrm{X}, \mathrm{Y}, \mathrm{Z}$ axes linear positioning measurements. The measuring stand consisted of a DMC 
Compensation unit readings describing environmental conditions for DMC $635 \mathrm{~V}$ ECOLINE vertical machining centre measurements Table 1

\begin{tabular}{|c|c|c|c|c|c|c|}
\hline \multirow[t]{2}{*}{ Dane } & \multicolumn{2}{|c|}{ Axis $\mathrm{X}$} & \multicolumn{2}{|c|}{ Axis Y } & \multicolumn{2}{|c|}{ Axis Z } \\
\hline & Start & End & Start & End & Start & End \\
\hline Air temperature $\left[{ }^{\circ} \mathrm{C}\right]$ & 22.99 & 22.94 & 23.09 & 22.86 & 23.20 & 22.97 \\
\hline Air pressure $[\mathrm{hPa}]$ & 1004.80 & 1004.80 & 1004.40 & 1004.40 & 1004.20 & 1004.00 \\
\hline Relative humidity [\%] & 31.19 & 31.96 & 32.01 & 32.34 & 31.93 & 32.00 \\
\hline Material temperature $\left[{ }^{\circ} \mathrm{C}\right]$ & 21.11 & 21.14 & 21.20 & 21.22 & 21.34 & 21.32 \\
\hline Environmental parameter & $\begin{array}{c}316406.88 \\
\times 10^{-6}\end{array}$ & $\begin{array}{c}316406.75 \\
\times 10^{-6}\end{array}$ & $\begin{array}{c}316406.63 \\
\times 10^{-6}\end{array}$ & $\begin{array}{c}316406.48 \\
\times 10^{-6}\end{array}$ & $\begin{array}{c}316406.16 \\
\times 10^{-6}\end{array}$ & $\begin{array}{c}316406.16 \\
\times 10^{-6}\end{array}$ \\
\hline
\end{tabular}

$635 \mathrm{~V}$ ecoline vertical machining centre, a laser head, a laser interferometer, linear retroreflectors, compensation unit and a computer of specific hardware requirements for the use of XL80 laser (Fig. 3a). Optics accessories were mounted directly on the spindle and the tool table and synchronised with XL80 laser. The measurement consisted in table motion measurement in the following steps: for X-axis by $50 \mathrm{~mm}$ (in the range of $0 \div 600 \mathrm{~mm}$ ), for Y-axis by $20 \mathrm{~mm}$ (in the range of $0 \div 460 \mathrm{~mm}$ ) and for Z-axis by $20 \mathrm{~mm}$ (in the range of $0 \div 440 \mathrm{~mm}$ ) as well as in registering the results at a given measuring point. The measurement was repeated three times for each axis. All measurements were conducted with no load, following proper preheating of the machine and at constant feedrate $v_{f}=$ const .

DMU 65 MonoBlock vertical 5-axis machining centre measurements were carried out in workshop conditions, with the application of XL80 laser system with rotary axis calibrator XR20-W (Fig. 3b). The measurement methodology included angular positioning accuracy measurement. XR20-W rotary axis calibrator was mounted in the centre of the machine tool table and configured with XL80 system. The tests consisted in performing a $360^{\circ}$ rotation of the table at $30^{\circ}$ steps and returning to the starting position of $0^{\circ}$. The system was stopped for 3 seconds at each measuring point for measurement data collection. Each test was repeated three times.

CTX 310 ECOLINE numerical control turning centre measurements were conducted in workshop conditions with the use of XL80 laser system with rotary axis calibrator XR20-W. The measuring stands are presented in Fig. 3c. The methodology consisted of angular positioning of the machine tool measurement. Rotary axis calibrator was mounted in lathe chuck and synchronised with XL80 laser. The measurements procedure consisted in performing a $360^{\circ}$ rotation of the lathe chuck at the steps of $20^{\circ}$ and returning to the starting position of $0^{\circ}$. The measurement was stopped for 3 seconds at each measuring point for data collection and each procedure was repeated three times.

The process of calibration with XR20-W system is fully automated. XR20-W calibrator is supplied with servocontrolled battery drive, and data capture is synchronised with axis motion. It results in the whole process being automated with no operator intervention required during data capture. Renishaw laser system is a non-contact reference measurement, characterised by high integrity, operated wirelessly and remotely from the tested axis. All measurements were conducted with no load and with prior preheating of the machine as per manufacturer instructions.

Linear axis measurements not exceeding $2000 \mathrm{~mm}$ should consist of minimum five measurements per metre. In set positions measurements are carried out with the adherence to a standard cycle procedure, i.e. at least twice in each direction, as per interferometer software specifications.

\section{Research results and analysis}

\subsection{DMC 635 v ECOLINE vertical machining centre technical condition assessment}

Experimental tests provided data of linear positioning errors in $\mathrm{X}, \mathrm{Y}, \mathrm{Z}$ axes in the forward $(\uparrow)$ and reverse $(\downarrow)$ direction. Based on these results the following measurements were carried out: unidirectional and bidirectional accuracy of positioning of axis (A, A $\uparrow, A \downarrow)$, unidirectional repeatability of positioning (forward $\mathrm{R} \uparrow$; reverse $\mathrm{R} \downarrow$ ) as well as reversal value of an axis (B).

Marked on the horizontal axis there is machine table motion value, whereas on the vertical axis - error motion in micrometres. Figure 4 and its table present measurement results of $\mathrm{X}$-axis. The collated data indicates that bidirectional and unidirectional accuracy of positioning of axis $\mathrm{A} \uparrow$ and $\mathrm{A} \downarrow$, as well as unidirectional repeatability of positioning $\mathrm{R} \uparrow$ and $\mathrm{R} \downarrow$ as well as reversal value of an axis $\mathrm{B}$ do not exceed tolerance standards as per the norm.

Figure 5 and incorporated table show linear error motions in the Y-axis. These results present bidirectional accuracy A of positioning of Y-axis, unidirectional accuracy of positioning of axis $\mathrm{A} \uparrow$ and $\mathrm{A} \downarrow$, as well as unidirectional repeatability of positioning $R \uparrow$ and $R \downarrow$ as well as reversal value of an axis $B$. It can be observed that error values increase with the increase of distance from the target and acquire maximum values at the distance of $460 \mathrm{~mm}$. Similarly as in the case of X-axis, all determined parameters are within the tolerance. 
a)

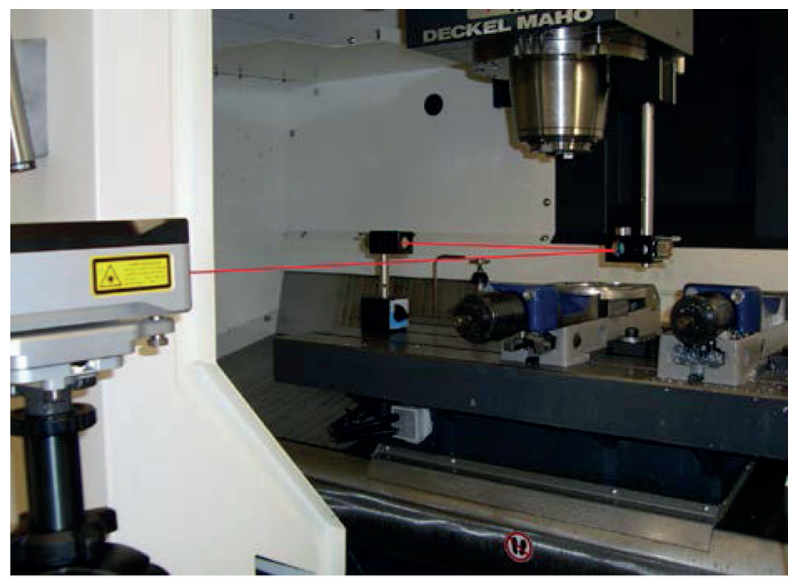

b)

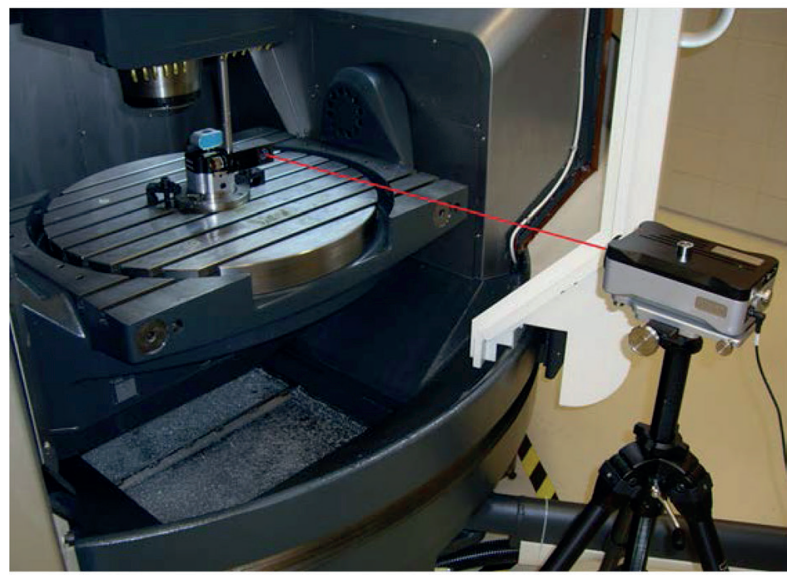

c)

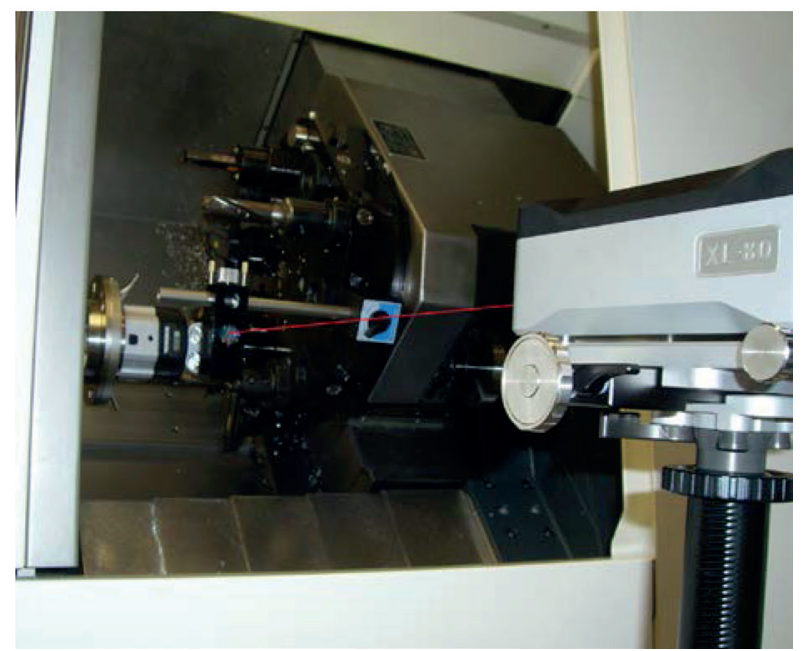

Fig. 3 Setting up and performing positioning error motion and repeatability of:

a) DMC 635 V ECOLINE vertical machining centre,

b) DMU 65 MonoBlock vertical 5-axis machining centre,

c) CTX 310 ECOLINE numerical control turning centre

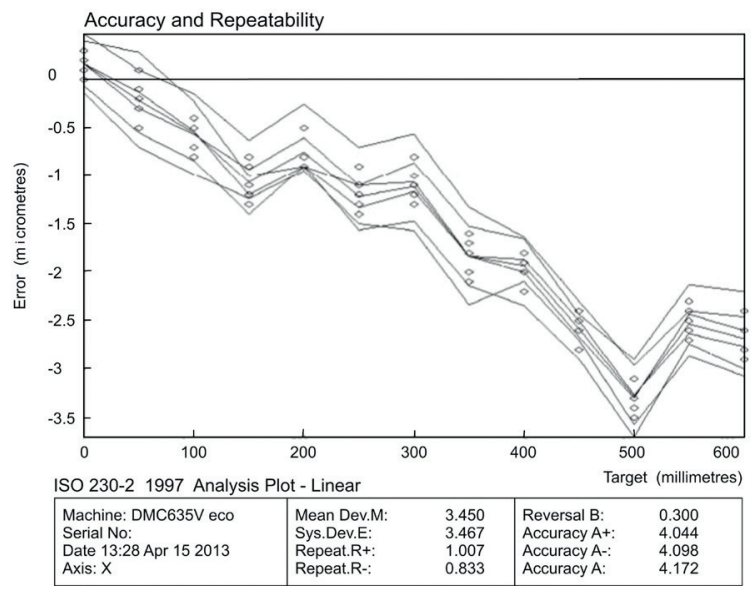

Fig. 4 Linear positioning error motion in the X-axis of DMC 635 $V$ ecoline vertical machining centre

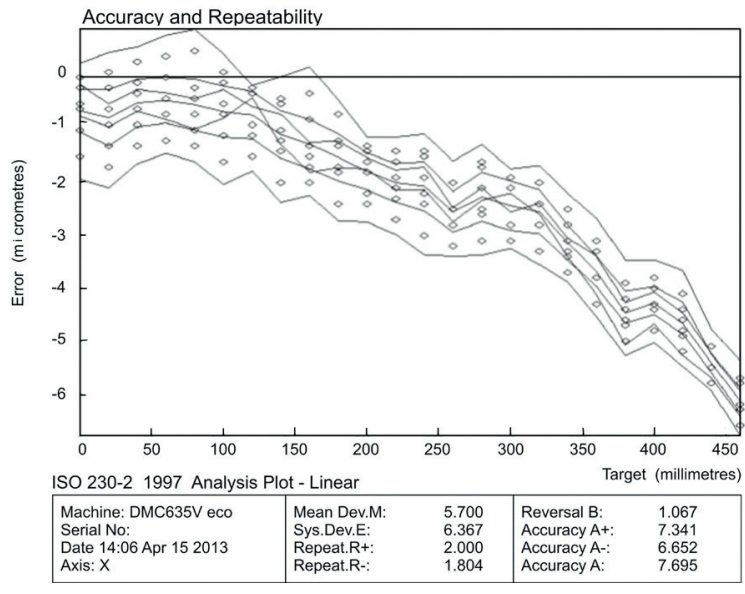

Fig. 5 Linear positioning error motion in the Y-axis of DMC $635 \mathrm{~V}$ ecoline vertical machining centre

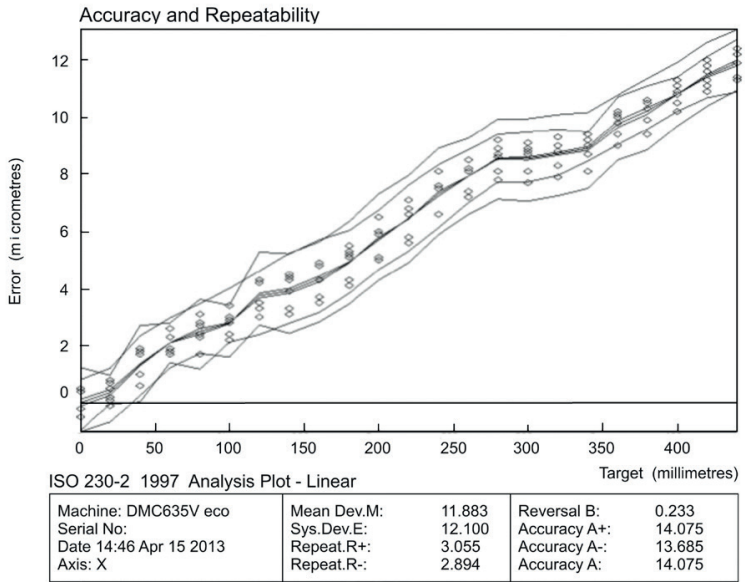

Fig. 6 Linear positioning error motion in the Z-axis of DMC $635 \mathrm{~V}$ ecoline vertical machining centre 
Analogical results, collected in Fig. 6, were obtained in Z-axis measurements. In comparison with $\mathrm{X}$ and $\mathrm{Y}$-axis, where maximum values amount to $6-8 \mu \mathrm{m}$, the measured error motion values were doubled and within the range of $12-14 \mu \mathrm{m}$. Nonetheless, all parameters (A, $\mathrm{A} \uparrow, \mathrm{A} \downarrow, \mathrm{R} \uparrow, \mathrm{R} \downarrow, \mathrm{B})$ are within the limits of ISO-230 standard.

\subsection{DMU 65 MonoBlock vertical 5-axis machining centre technical condition assessment}

Figure 7 presents mean unidirectional accuracy of positioning of axis in the forward $(\uparrow)$ and reverse $(\downarrow)$ direction. The analysis of the diagram indicates that the highest error motion value is observed at the angle of $210^{\circ}$.

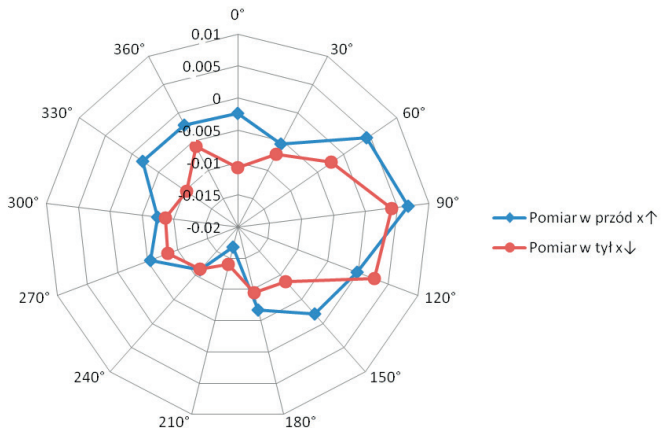

Fig. 7 Mean angular deviation of DMU 65 monoBLOCK

\subsection{CTX 310 ECOLINE numerical control turning centre technical condition assessment}

Figure 8 presents mean unidirectional accuracy of positioning of axis in the forward $(\uparrow)$ and reverse $(\downarrow)$ direction. The analysis of the diagram indicates that the highest error motion value is observed at the angle of $240^{\circ}$.

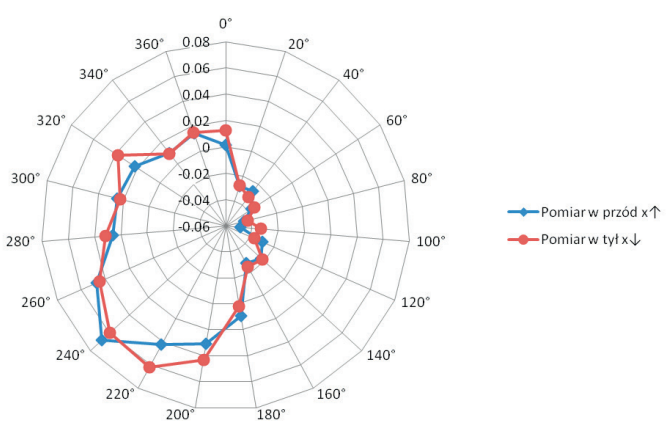

Fig. 8 Mean angular deviation of CTX 310 ECOLINE

Values of axis positioning accuracy (A, A $\uparrow, \mathrm{A} \downarrow, \mathrm{R} \uparrow, \mathrm{R} \downarrow, \mathrm{B})$ derived in tests will provide the basis for future model for error prognosis, which will apply the methods of Artificial Intelligence. This requires, however, systematic diagnostic measurements with a view to creating geometric accuracy history of a machine tool, based on which such a model could be developed. It does, nonetheless, open the gate for downloading obtained results to the type series of machine tools in service. The goal set by the authors of this paper, i.e. creation of models in question is believed to produce notable benefits connected with practical application, which would allow a manufacturer to estimate the future condition of the machine and to take necessary measures to compensate and minimise appearing errors.

\section{Conclusions}

Conducted experimental tests and the analysis of their results lead to the formulation of the following conclusions:

1. Laser interferometer is at present the most precise and universal measuring instrument applied in CNC machine diagnostics. The scope of its applications includes conducting measurements of diverse geometric and kinematic parameters of a machine tool, which is directly reflected in the improvement of the general technical condition of machines through immediate error compensation. Among its most notable features, which must be mentioned is its streamlined operation procedures and intuitive software, generating reports according to current norms.

2. Conducted diagnostics of the analysed machine tool systems proved that none of the determined parameters $(\mathrm{A}, \mathrm{A} \uparrow, \mathrm{A} \downarrow$, $\mathrm{R} \uparrow, \mathrm{R} \downarrow, \mathrm{B})$ exceeds the tolerance values described in the Polish Norm PN-ISO-230. It could be, therefore, stated that the machine tool centres in questions are in good technical condition. Nevertheless, frequent systematic diagnostic testing and required regulation of, e.g. controllers or drives is of utmost importance.

3. Maximum linear positioning error motion values in the case of DMC $635 \mathrm{~V}$ ECOLINE vertical machining centre were observed in extreme positions in each axis of the machine tool. A recommended method for prevention of machining errors which result from the local character of such an error is to avoid machining in the identified workspace of the machine tool.

4. The change of laser optics is obligatory in error motions of axis testing when axis is changed. This solution is, however, inefficient and time-consuming. Furthermore, it leads to the situation when all measurements must be repeatedly conducted for each particular axis, bearing in mind that each laser or optics position change necessitates calibration of the whole system.

5. The selection of a method and a measuring tool should be contingent on: accuracy requirements, the cost of the device, time required for testing and accessibility of the device. 


\section{References}

[1] KURIC, I.: New Methods and Trends in Product Development and Process Planning. Academic J. of Manufacturing Engineering. Editura Politehnica: Scientific Papers, vol. 9, No. 1, 2011, 83-88, Cluj-Napoca. ISSN 1583-7904

[2] CZAN, A., TILlOVA, E., SEMCER, J., PILC, J.: Surface and Subsurface Residual Stresses After Machining and their Analysis by x-ray Diffraction, Communications - Scientific Letters of the University of Zilina, No. 2, 2013, 69-76. ISSN 1335-4205

[3] DUGIN, A., POPOV, A.: Increasing the Accuracy of the Effect of Processing Materials and Cutting Tool Wear on the Ploughing Force Values. Manufacturing Technology, vol. 13, No. 2, 2013, 169-173. ISSN 1213-2489

[4] STANCEKOVA, D., SEMCER, J., DERBAS, M., KURNAVA, T.: Methods of Measuring of Residual Stresses and Evaluation of Residual State of Functional Surfaces by x-ray Diffractometric Methods, J. Manufacturing Technology, vol. 13, No. 4, 2013, 547552, ISSN: 1213-2489.

[5] VARGA, G.: Effects of Technological Parameters on the Surface Texture of Burnished Surfaces, Key Engineering Materials, Precision Machining VII, vol. 581, 2014, 403-408. ISSN 1013-9826, doi:10.4028/www.scientific.net/KEM.581.403

[6] KUMICAKOVA, D., GORSKI, F., MILECKI, A., GRAJEWSKI, D.: Utilization of Advanced Simulation Methods for Solving of Assembly Processes Automation Partial Tasks. Manufacturing Technology: J. for Science, Research and Production, vol. 13, No. 4, 2013, 478-485. ISSN 1213-2489

[7] NAKAZAWA, H., ITO, K.: Measurement System of Contouring Accuracy on NC Machine Tools. Bull. Japan Soc. Prec. Eng., 12, 4: 189, 1978. Publisher Elsevier

[8] SAGA M., HANDRIK M., KOPAS P.: Contribution to Computer Simulation of Induction Bending of Large Diameter Pipes. Metalurgija (Metalurgy) 2010, vol. 49, No. 2, 498-502, ISSN 0543-5846

[9] SAGA, M., ZMINDAK, M., DEKYS, V., SAPIETOVA, A., SEGLA, S.: Selected Methods of Analysis and Synthesis of Mechanical Systems (in Slovak). VTS: University of Zilina, 2009, 360 p. ISBN 978-80-89276-17-2

[10] SAGA, M.: Development and Application of Selected Algorithms for Finite Element Optimization. Eds. SAGA, M. et al.: Advanced Methods in Computational and Experimental Mechanics. Pearson Education Limited, London, United Kingdom, 2013, 57-112, ISBN 978-1-78434-069-8

[11] SAPIETOVA, A., SAGA, M., NOVAK, P.: Multi-software Platform for Solving of Multibody Systems Synthesis. Communication - Scientific Letters of the University of Zilina, vol. 14, No. 3, 2012, Zilina, pp. 43- 48, ISSN 1335-4205

[12] HONCZARENKO, J. KWASNIEWICZ, J.: New Measurement Systems for Verifying the Accuracy of CNC Machine Tools (in Polish), Mechanik, 12, 2008, 1012-1016. Publisher: Agenda Wydawnicza SIMP. Poland.

[13] CHEN, J. S., KOU, T. W., CHIOU, S. H.: Geometric Error Calibration of Multi-axis Machines using an Auto-alignment Laser Interferometer. J. of the Intern. Societies for Precision Engineering and Nanotechnology, 23, 1999, 243-252. Publisher Elsevier

[14] IWASAWA, K., IWAMA, A., MITSUI, K.: Development of a Measuring Method for Several Types of Programmed Tool Paths for NC Machine Tools using a Laser Displacement Interferometer and a Rotary Encoder, Precision Engineering, 28, 4, 2004, 399-408. Publisher Elsevier

[15] JOZWIK, J., KURIC, I. SAGA, M., LONKWIC, P.: Diagnostics of CNC Machine Tools in Manufacturing Process with Laser Interferometer Technology. Manufacturing Technology, 2014 , vol. 14, No. 1, 23-30, ISSN 1213-2489

[16] JOZWIK, J., KURIC, I.: Non-contact Diagnostic Systems of CNC Machine Tools (in Polish). $14^{\text {th }}$ Intern. Conference Automation in Production Planning and Manufacturing, Zilina, 2013

[17] JOZWIK, J., LONKWIC, P., SAGA, M., KURIC, I.: R-Test Static Measurement of the 5-Axis CNC Machining Centre Rotary Axis Kinematic Centre Error, accepted to print in Manufacturing Technology, vol. 14, No. 2, 2014, ISSN 1213-2489

[18] KRYNKE, M., SELEJDAK, J., BORKOWSKI, S.: Diagnosis and Damage of Bearings. Manufacturing Technology, vol. 12, No. 13, 2012, 140-144. ISSN 1213-2489

[19] MAYER, K., PEXA, M., PAVLU, J.: Impact of Technical Diagnostics Interval on Machinery Maintenance. Manufacturing Technology, vol. 12, No. 12, 2012, 42-46. ISSN 1213-2489

[20] SHIRINZADEH, B., TEOH, P. L.: Laser Interferometry-based Guidance Methodology for high Precision Positioning of Mechanisms and Robots. Robotics and Computer-Integrated Manufacturing 26, 2010, 74-82

[21] CASTROA, H. F. F., BURDEKINB, M.: Calibration System Based on a Laser Interferometer for Kinematic Accuracy Assessment on Machine Tools. Inter. J. of Machine Tools \& Manufacture, 46, 2006, 89-97. Publisher Elsevier

[22] KURIC, I., DURICA, I., MADUDA, M.: Accuracy and Calibration of CNC Machines. Scientific Bulletin, Series C, Fascicle: Mechanics, Tribology, Machine Manufacturing Technology, vol. XXIII, 2010, 113-118

[23] MAJDA, P.: The Influence of Geometric Errors Compensation of a CNC Machine Tool on the Accuracy of Movement with Circular Interpolation. Advances in Manufacturing Science and Technology, vol. 36, No. 2, 2012, 59-67. Publisher Elsevier

$174 \cdot$ COMMUNICATIONS 3A/2014 
[24] CUBOnOVA, N.: Postprocessing of CL Data in CAD/CAM System Edgecam using the Constructor of Postprocessors, Manufacturing Technology: J. for Science, Research and Production, vol. 13, No. 2, 2013, 158-164. ISSN 1213-2489

[25] SCHWENKE, H., KNAPP, W., HAITJEMA, H., WECKENMANN, A., SCHMITTE, R., DELBRESSINE, F.: Geometric Error Measurement and Compensation of Machines - An update. CIRP Annals - Manufacturing Technology, vol. 57, 2, 2008, 660-675. Publisher Elsevier

[26] http://en.dmgmori.com/(z dn. 01/06/2014r.)

[27] http://www.renishaw.pl/pl/1030.aspx (z dn. 01/06/2014r.). 